Fifth International Conference on Sustainable Construction Materials and

Technologies. http://www.claisse.info/Proceedings.htm

SCMT5

London, UK, July 14-17, 2019

\title{
THE EFFECT OF SEEDING OF SYNTHESIZED C-S-H WITH DIFFERENT C/S ON EARLY HYDRATION REACTION OF ALITE
}

\author{
Yumetoki Abe ${ }^{1 a}$, Yuka Morinaga ${ }^{1 b}$, Toyoharu Nawa ${ }^{1 c}$ and Yogarajah \\ Elakneswaran $^{1 d}$
}

\footnotetext{
${ }^{1}$ Division of Sustainable Resources Engineering, Hokkaido University, Japan. E-mail: 1a $<$ dreamer-of-hokudai@eis.hokudai.ac.jp>, $\quad$ 1b $<$ glico611@eis.hokudai.ac.jp>, 1c<nawa@eng.hokudai.ac.jp>, 1d<elakneswaran@eng.hokudai.ac.jp>.
}

\begin{abstract}
Cementitious materials containing admixtures such as industrial waste or by-products is highly expected for environment and sustainable development. These materials have problems with slow hydration, and the use of a hydration accelerator is an effective solution. Therefore, in this study, authors focused on synthesized C-S-H among hydration accelerators, detailed characterization was carried out on the synthesized C$\mathrm{S}-\mathrm{H}$ with different $\mathrm{Ca} / \mathrm{Si}$ ratio(C/S), and the effect of this $\mathrm{C}-\mathrm{S}-\mathrm{H}$ on the initial hydration reaction of alite was investigated. As a result, it was elucidated that seeding greatly influences the precipitation of $\mathrm{C}-\mathrm{S}-\mathrm{H}$ rather than the dissolution of alite. Moreover, it was confirmed that addition of synthesized C-S-H with low C/S promotes initial C-S$\mathrm{H}$ precipitation, while hydration rate and amount of $\mathrm{C}-\mathrm{S}-\mathrm{H}$ precipitation at the late hydration stage and MCL of generated C-S-H don't depend on C/S of synthesized C$\mathrm{S}-\mathrm{H}$. According to these results, addition of synthesized C-S-H with low $\mathrm{C} / \mathrm{S}$ to cementitious materials may be solve the problem of initial strength of cementitious materials using admixtures such as industrial waste or by-products.
\end{abstract}

Keywords: Cementitious materials, hydration accelerators.

\section{INTRODUCTION}

Cementitious materials are required roles such as construction material, efficient use of industrial waste or by-products, and isolating radioactive waste. The use of these admixtures is highly expected for environment and sustainable development. Cementitious materials using admixtures has been shown to have several effects; suppressing the temperature rise by the heat of hydration and alkali-silica reaction (ASR) from previous studies, but there is a problem that initial strength is low and it 
takes time to use effectively. For sustainable use of cementitious materials, it is essential to understand calcium silicate hydrate $(\mathrm{C}-\mathrm{S}-\mathrm{H})$, the main hydration product of cement, and the use of a hydration accelerator such as calcium chloride and nanoparticles.

Cement consists of four minerals mixed with a small amount of gypsum. Among them, alite and belite produce $\mathrm{Ca}(\mathrm{OH})_{2}$ and $\mathrm{C}-\mathrm{S}-\mathrm{H}$ by reaction with water. Especially, alite which accounts for about $60 \%$ of the weight of cement has been extensively studied as a model mineral of cement, since it has a great influence on mixing time and initial strength. Because of the difference in heat value with respect to time, alite can divide the hydration reaction mainly into four stages: rapid heat generation and dissolution of alite after starting hydration (initial reaction), a period during which the hydration rate drops markedly and almost no heat is observed (induction period), a period during which the heat becomes active again and the precipitation of C-S-H starts (acceleration period), and a stage at which the reaction rate gradually decreases and the hydration reaction goes to completion (deceleration period). Among them, the mechanism of the induction period and the transition from the induction period to the acceleration period have not been elucidated yet.

As a method of considering such hydration mechanism of alite, there is a method to clarify elements predominant in the hydration reaction in a system in which hydration reaction rate of alite is changed by adding an accelerator or a retarder. Inorganic salts [Oyama et al., 2016; Awamura and Nawa, 2013] such as calcium chloride and nucleating agents [Land and Stephan, 2015; Nicolaeu et al., 2013; Thomas et al., 2009] such as nanoparticles or C-S-H have been reported as promoters in cement hydration. In nucleating agent, it can be divided into Seeding (Nucleating Seeding) which adds $\mathrm{C}-\mathrm{S}-\mathrm{H}$ and nanoparticles other than C-S-H. Focusing on Seeding, for example, it is reported that the difference in three dimension aggregation structure of $\mathrm{C}-\mathrm{S}-\mathrm{H}$ particles affects the hydration rate of alite [Nicoleau, 2010] because C-S-H species (Seed) may act as a generation site for heterogeneous nucleation in the initial hydration of alite. However, in this study, $\mathrm{Ca} / \mathrm{Si}$ ratio $(\mathrm{C} / \mathrm{S})$ which is an important factor in the aggregated structure of C-S-H has not been investigated.

As a study on C/S of synthesized C-S-H used for Seeding, it is reported that the use of synthesized C-S-H with low C/S promotes initial hydration of alite, but in the later stage of hydration the heat value becomes almost equal regardless of $\mathrm{C} / \mathrm{S}$ of synthesized C-S-H [Alizadeh, 2009]. However, the characterization of synthesized C$\mathrm{S}-\mathrm{H}$ was not done in this report, and the difference between added C-S-H and generated $\mathrm{C}-\mathrm{S}-\mathrm{H}$ was not clarified. Therefore, at first in this study, the characterization of synthesized C-S-H which was prepared was carried out. In addition, a hydration experiment of alite with synthesized C-S-H of different C/S was conducted. From the viewpoint of the hydration process of alite and the mean chain length of silicate (MCL) of silicate chain of generated $\mathrm{C}-\mathrm{S}-\mathrm{H}$, we investigated the effect of Seeding of synthesized $\mathrm{C}-\mathrm{S}-\mathrm{H}$ with different $\mathrm{C} / \mathrm{S}$ on hydrating reaction of alite. 


\section{EXPERIMENTAL INVESTIGATION}

\section{Preparation of Synthesized C-S-H}

In this study, synthesized C-S-H having $\mathrm{C} / \mathrm{S}=0.8$ and 1.5 were prepared (CSH-0.8 and $\mathrm{CSH}-1.5) . \mathrm{Ca}(\mathrm{OH})_{2}, \mathrm{SiO}_{2}$ and pure water were used. $\mathrm{Ca}(\mathrm{OH})_{2}$ and $\mathrm{SiO}_{2}$ were weighed and mixed with pure water so as to have a water powder rate of 20 . After that, shake mixing was carried out every one hour for up to 3 hours after starting mixing, and a hydrothermal reaction was carried out for 10 days in a thermostatic chamber at $50{ }^{\circ} \mathrm{C}$. After this reaction, the solid phase and the liquid phase were separated by a membrane filter $(\varphi=0.45 \mu \mathrm{m})$. The solid phase was filtered by suction with a Buchner funnel and washed by distilled water three times. By using this method, remaining $\mathrm{Ca}(\mathrm{OH})_{2}$ was removed. After that, it was dried using a freeze dryer for 2 days. The liquid phase was sealed with nitrogen and then allowed to stand until it was used for measurement of ICP-AES.

\section{Preparation of Hydration Sample and Measurements}

In this study, alite manufactured by Taiheiyo Consultant was used, and CSH-0.8 and CSH-1.5 were used as additives. Distilled water at room temperature was used for the mixing water, and the water powder ratio (water (g) / alite (g)) was set to 0.5. Distilled water was added to the weighed alite and mixed by hand for 5 minutes. In the synthesized C-S-H addition system, synthesized C-S-H was previously mixed with distilled water at $1 \%$ weight with respect to alite. In order to prevent paste bleeding, we mixed the sample at 30 minute intervals up to 8 hours from the start of hydration. Then the paste was sealed with nitrogen and left at $20{ }^{\circ} \mathrm{C}$. Completed samples were immersed in acetone for 1 hour and dried in a drying oven at $40{ }^{\circ} \mathrm{C}$ for 8 hours. The dried sample was pulverized manually for 5 minutes using an agate mortar and used for various measurements.

An X-ray generator for Rigaku Multi Flex was used for XRD measurement. The measurement conditions were the target $\mathrm{CuK} \alpha$, tube voltage $40 \mathrm{kV}$, tube current 40 $\mathrm{mA}$, scanning range 5 to $70\left({ }^{\circ} 2 \theta\right)$, sampling width $0.02\left({ }^{\circ} 2 \theta\right)$, scanning speed 6.5 $\left({ }^{\circ} 2 \theta / \mathrm{s}\right)$. In order to consider the amorphous mass contained in the sample, the internal standard method was selected. Corundum $\left(\alpha-\mathrm{Al}_{2} \mathrm{O}_{3}\right)$ was added at $10 \%$ of sample. SIROQUANT Version 4.0 was used for Rietveld analysis. The amorphous content in the hydrated sample was calculated according to the formula (1) and the quantitative value of each mineral according to the formula (2). The amount of unhydrated mineral in alite was calculated by using loss of ignition (LOI). Furthermore, hydration rate of alite obtained by XRD was calculated by the formula (3).

$$
A=\frac{100}{100-S} \times\left(1-\frac{S}{S_{R}}\right) \times 100
$$

In the formula (1), $\mathrm{A}$ is the amorphous mass (\%), $\mathrm{S}$ is the mixing amount (\%) of corundum, $S_{\mathrm{R}}$ is the quantitative value $(\%)$ of corundum. 


$$
M=M_{X R D} \times \frac{100}{100-L}
$$

In the formula (2), $\mathrm{M}$ is the quantitative value (\%) of each mineral, $\mathrm{M}_{\mathrm{XRD}}$ is the quantitative value (\%) by Rietveld analysis, and L is LOI (wt\%).

$$
\alpha_{X R D}=\frac{M_{0}-M_{t}}{M_{0}} \times 100
$$

In the formula (3), $\alpha_{\mathrm{XRD}}$ is the XRD hydration rate (\%), $\mathrm{M}_{\mathrm{o}}$ is the quantitative value (\%) of unhydrated alite and $\mathrm{M}_{\mathrm{t}}$ is the quantitative value (\%) of alite in each time.

Bruker MSL 400 was used for ${ }^{29} \mathrm{Si}$ MAS NMR measurement. Measurement was carried out using a $7 \mathrm{~mm}$ MAS probe at a rotation frequency of $4 \mathrm{kHz}$. Synthesized C$\mathrm{S}-\mathrm{H}$ was measured using a $90^{\circ}$ pulse width of $5 \mu \mathrm{s}$, an accumulation number of 2000 , a waiting time of $45 \mathrm{~s}$, and a reference material of $\left[\mathrm{Si}\left(\mathrm{CH}_{3}\right)_{3}\right]_{8} \mathrm{Si}_{8} \mathrm{O}_{20}$. For the measurement of the hydrated sample, the $30^{\circ}$ pulse width was $1.7 \mu \mathrm{s}$, the accumulation number was 1200 times, the waiting time was $3 \mathrm{~s}$, and the reference substance was $\left[\mathrm{Si}\left(\mathrm{CH}_{3}\right)_{3}\right]_{8} \mathrm{Si}_{8} \mathrm{O}_{20}$. In addition, WinNuts is used for analysis software and Lorentz function is used for fitting. The relative abundance rate of each signal $\left(Q^{0}, Q^{1}, Q^{2}\right.$, and $\mathrm{Q}^{2}$ b) was calculated and MCL was calculated by the formula (4).

$$
\mathrm{MCL}=2 \times \frac{Q^{1}+Q_{b}^{2}+Q_{p}^{2}}{Q^{1}}
$$

The sample used for ICP-AES was diluted so that the concentration of various ions $(\mathrm{Ca}, \mathrm{Si})$ was $2 \mathrm{ppm}(\mathrm{mg} / \mathrm{L})$ or less. Using an electronic balance, the dilution was made on the basis of weight.

The $\mathrm{C} / \mathrm{S}$ of the synthesized C-S-H was observed by XRF measurement. Using an element monitor EA1200VX, a fluorescent X-ray analyzer manufactured by Hitachi High-Tech Sciences, the measurement conditions were an excitation voltage of $50 \mathrm{kV}$, a tube current of $1000 \mu \mathrm{A}$, and a vacuum atmosphere.

In order to calculate the specific surface area of the synthesized $\mathrm{C}-\mathrm{S}-\mathrm{H}$, water vapor adsorption measurement was carried out. Each sample was subjected to vacuum degassing drying for 1 hour. The measurement conditions were an equilibrium time of $120 \mathrm{~s}$, a permissible pressure range of $0.05 \mathrm{mmHg}$, a measuring temperature of $20^{\circ} \mathrm{C}$, and a measured relative vapor pressure range of 0.05 to 0.4 . The specific surface was calculated by the BET method.

The mixture proportions and fresh concrete properties of the mixtures are presented in Table 3. To evaluate retention of slump of the concrete mixtures, slump was measured twice: (1) immediately after mixing was done; and, (2) 30 minutes later. In general, the concrete mixtures retained their workability, although the slump was generally reduced by about 10 to $25 \mathrm{~mm}$. 
The mixture proportions and fresh concrete properties of the mixtures are presented in Table 3. To evaluate retention of slump of the concrete mixtures, slump was measured twice: (1) immediately after mixing was done; and, (2) 30 minutes later. In general, the concrete mixtures retained their workability, although the slump was generally reduced by about 10 to $25 \mathrm{~mm}$.

\section{RESULTS AND DISCUSSIONS}

\section{Characterization of Synthesized C-S-H}

At first, we conpared the XRD diffraction pattern of synthesized C-S-H in this study (CSH-0.8, CSH-1.5) with the pattern of previous studies [for example, Myers et al., 2015]. The X-ray diffraction patterns is shown in Figure. 1. According to this comparison, CSH-0.8 and CSH-1.5 were determined to be tobermorite type C-S-H.

Second, we investigated the abundance proportions of bonding state of silicate chain $\left(\mathrm{Q}^{0}, \mathrm{Q}^{1}, \mathrm{Q}_{\mathrm{p}}{ }_{\mathrm{p}}\right.$, and $\left.\mathrm{Q}^{2} \mathrm{~b}\right), \mathrm{C} / \mathrm{S}$ and specific surface area. These data were calculated by XRD analysis, ${ }^{29} \mathrm{Si}$ MAS NMR analysis, and water vapor sorption measurement respectively. These data are shown in Table. 1. The measured $\mathrm{C} / \mathrm{S}$ of $\mathrm{CSH}-0.8$ indicated 0.802 and roughly agreed with 0.8 . On the other hand, for $\mathrm{CSH}-1.5$, the measured $\mathrm{C} / \mathrm{S}$ was 1.25 , which was lower than 1.5. In the generation process of $\mathrm{CSH}$ 1.5 , it is considered that unreacted $\mathrm{Ca}(\mathrm{OH})_{2}$ precipitated on the surface of the synthesized $\mathrm{C}-\mathrm{S}-\mathrm{H}$, and $\mathrm{Ca}(\mathrm{OH})_{2}$ was removed by the washing.

Figure. 2 shows the comparison data of the equilibrium solution of C-S-H prepared in this study with the previous study (Jennings, 1986), and curve A is said to a

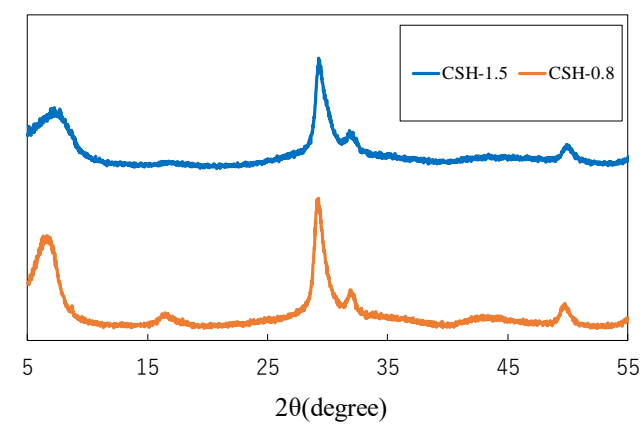

Figure. 1. X-ray diffraction pattern of synthesized C-S-H

Table 1. Calculated data of synthesized C-S-H

\begin{tabular}{|l|l|l|l|l|l|l|}
\hline Sample & $\mathrm{C} / \mathrm{S}$ & $\mathrm{Q}^{1}(\%)$ & $\mathrm{Q}^{2}{ }_{\mathrm{b}}(\%)$ & $\mathrm{Q}_{\mathrm{p}}^{2}(\%)$ & $\mathrm{MCL}$ & $\begin{array}{l}\text { Specific surface } \\
\text { area }\left(\mathrm{m}^{2} / \mathrm{g}\right)\end{array}$ \\
\hline CSH-0.8 & 0.802 & 17.7 & 28.1 & 54.2 & 11.5 & 326 \\
\hline CSH-1.5 & 1.25 & 78.6 & 7.01 & 14.4 & 2.54 & 221 \\
\hline
\end{tabular}


tobermorite type C-S-H (C-S-H (I)). From the above experimental results, an estimated schematic of C-S-H structure can be proposed as Figure. 3, but Figure. 3 is a structural schematic diagram focused on the bonding state of the silicate chain of the synthesized $\mathrm{C}-\mathrm{S}-\mathrm{H}$. Although CSH-0.8 and CSH-1.5 are tobermorite-like, it is considered that the surface property and structure are different because the MCL of CSH-0.8 is 11.3 while the MCL of CSH-1.5 is 2.54 and because the ratio of $\mathrm{Q}^{2} \mathrm{~b}$ greatly varies depending on each synthesized $\mathrm{C}-\mathrm{S}-\mathrm{H}$.

\section{The Effect of C/S of Synthesized C-S-H on Alite Hydration}

Figure. 4 shows the rate of heat evolution accompanying time change measured by the calorimetry. Hereafter, CSH-0.8, CSH-1.5, and without C-S-H added system is represented as

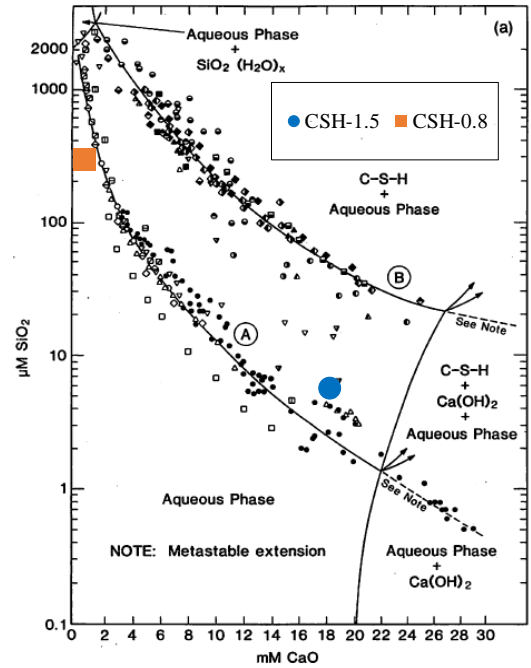

Figure 2. Comparison of concentration of $\mathrm{Si}$ and $\mathrm{Ca}$ ion with previous study

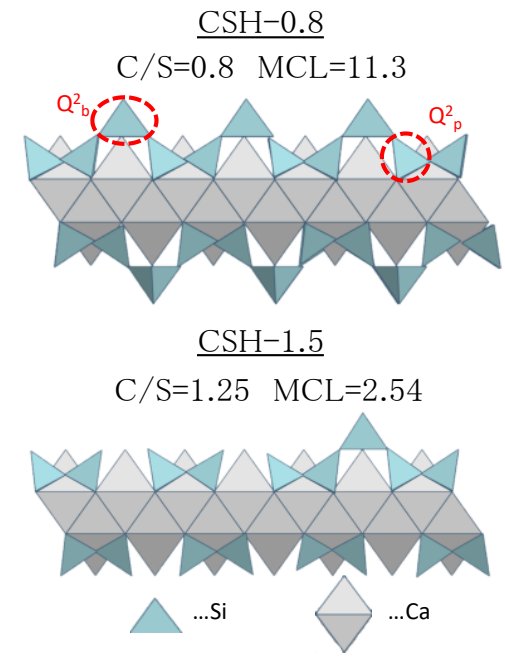

Figure 3. Schematic of C-S-H structure

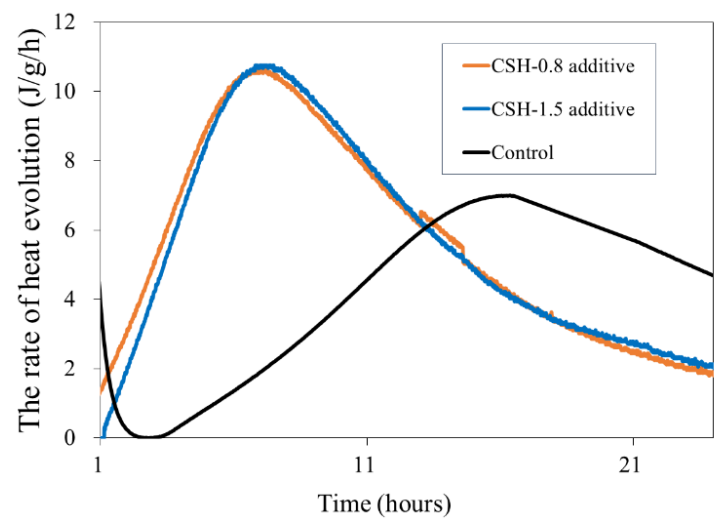

Figure 4. The rate of heat evolution vs elapsed time 
CSH-0.8 additive, CSH-1.5 additive and control respectively. This result is in agreement with the previous study [Thomas et al., 2009] that Seeding shortens the induction period and accelerates the transition to the acceleration period. Moreover, when authors focus on the $\mathrm{C} / \mathrm{S}$ of the synthesized $\mathrm{C}-\mathrm{S}-\mathrm{H}$, the start to the acceleration period was advanced faster in the $\mathrm{CSH}-0.8$ additive than in the $\mathrm{CSH}-1.5$ additive. On the other hand, the heat generation rate in the later age of hydration was constant regardless of $\mathrm{C} / \mathrm{S}$. This result was consistent with the previous study [Alizadeh et al., 2009] focusing on the $\mathrm{C} / \mathrm{S}$ of the synthesized C-S-H. Since the remaining amount of alite is obtained from the XRD/Rietveld method, the hydration ratio was judged to be the dissolution rate of alite. On the other hand, $\left(\mathrm{Q}_{1}+\mathrm{Q}_{2}\right) / \Sigma \mathrm{Q}_{\mathrm{n}}$ obtained by deconvolution of the ${ }^{29} \mathrm{Si}$ MAS NMR spectrum was judged to be the amount of C-S$\mathrm{H}$, because it represents a product of polymerized silicate. If all of the dissolved alite was consumed for the production of $\mathrm{C}-\mathrm{S}-\mathrm{H}$, the dissolution rate of alite and the precipitation of $\mathrm{C}-\mathrm{S}-\mathrm{H}$ should be equal, but these results do not agree [Hattori et al., 2011]. The cause of this is an intermediate phase existing time between $\mathrm{C}-\mathrm{S}-\mathrm{H}$ formation and dissolution of alite [Bellmann et al., 2010; Pustoger et al., 2016]. Therefore, when we consider the hydration reaction of alite, it is necessary to investigate both of the dissolution rate of alite and the precipitation of C-S-H [Nawa et al., 2015].

Figure. 5 and Figure. 6 show dissolution rate of alite and amount of C-S-H precipitation as a function of elapsed time respectively. In Figure. 5, the dissolution of alite didn't be proceeded by Seeding as compared with control, except for the change of the age of 1 to 6 hours in CSH-0.8 additive. On the other hand, from Figure. 6, the amount of C-S- H production increased in the synthesized C-S-H addition system compared to control. Moreover, these results confirmed that Seeding does not promote the dissolution of alite but promotes only $\mathrm{C}-\mathrm{S}-\mathrm{H}$ formation. In addition, the generation of C-S-H started earlier than CSH-1.5 additive and control, so it is considered that dissolution of alite was promoted by starting to the acceleration phase. Moreover, from Figure. 6, C-S-H was produced at age of 1 hour

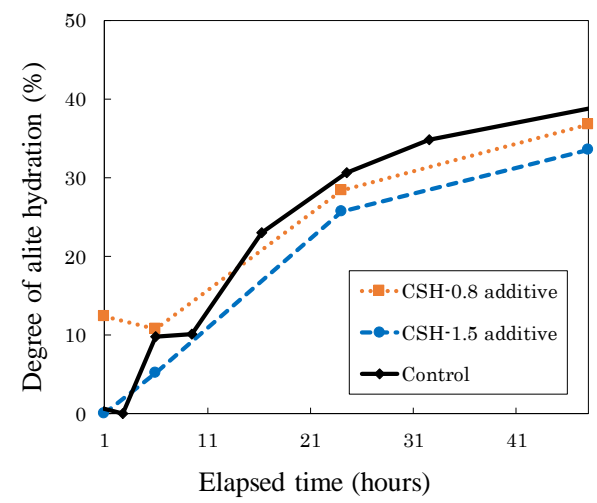

Figure 5. Dissolution rate of alite vs elapsed time

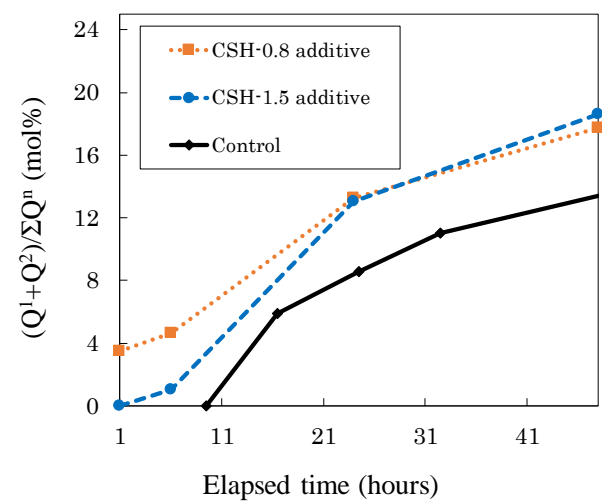

Figure 6. Amount of C-S-H precipitation vs elapsed time 
only in CSH-0.8 additive while it can be confirmed from Figure. 5 and Figure. 6 that the dissolution rate of alite and the amount of C-S-H are almost equal regardless of $\mathrm{C} / \mathrm{S}$ of synthesized C-S-H in the late hydration. Therefore, these tendency support the previous study [Alizadeh et al., 2009] which focus on the C/S of synthesized C-S-H.

Furthermore, authors compared the result of Figure. 4 with Figure. 5 and Figure. 6. While the effect of Seeding was not observed in the dissolution rate of alite except for $\mathrm{CSH}-0.8$ additive at 1 hour of age, Seeding affect the amount of $\mathrm{C}-\mathrm{S}-\mathrm{H}$ precipitation regardless of the age than control. In any system, a start of heat as seen in Figure. 4 is roughly in agreement with the start of C-S-H precipitation seen in Figure. 6. Therefore, it can be considered that the hydration heat after the induction period is caused not by dissolution of alite and consequent formation of intermediates but by $\mathrm{C}-\mathrm{S}-\mathrm{H}$ production from the intermediate phase.

Figure. 7 shows the relationship between the amount of C-S-H produced and MCL. The MCL of the synthesized C-S-H was indicated in 0 hour. In Figure. 7, decrease of MCL was observed with increasing amount of C-S-H in any system. This is consistent with the previous study [Awamura and Nawa, 2013] which report that there are two kinds of metastable C-S-H, and that C-S-H of long MCL was generated at first and C$\mathrm{S}-\mathrm{H}$ of short MCL was generated as the hydration proceed. In general, the MCL of generated C-S-H increases with proceeding cement hydration [Anderson et al., 2004], but this study focus on up to the age of 48 hours, so it is expected that the MCL will increase thereafter.

Moreover, the MCL of C-S-H produced in the initial stage of hydration in the synthesized C-S-H addition system was different from the MCL of the synthesized C$\mathrm{S}-\mathrm{H}$. From the result, it can be considered that $\mathrm{C}-\mathrm{S}-\mathrm{H}$ produced in the synthesized C$\mathrm{S}-\mathrm{H}$ addition system is the same as $\mathrm{C}-\mathrm{S}-\mathrm{H}$ produced in control. In other words, the generated C-S-H does not change by Seeding. Moreover, the previous study

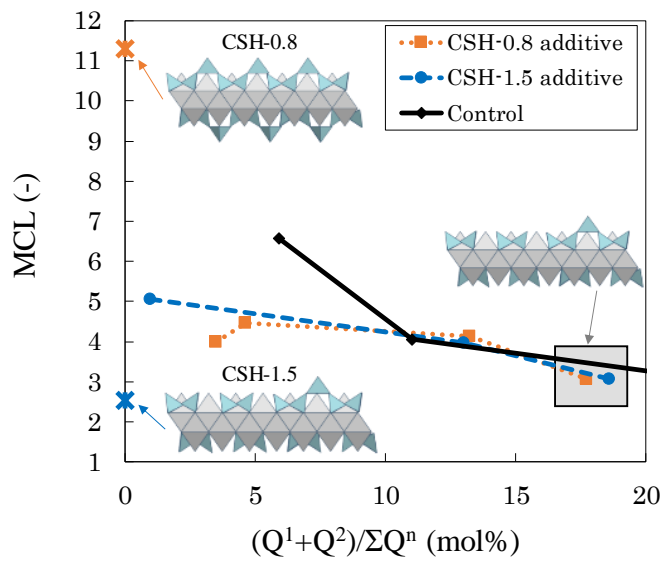

Figure 7. MCL vs amount of C-S-H precipitation

[Alizadeh et al., 2009] reported that the relative proportion of $\mathrm{Q}^{1}$ and $\mathrm{Q}^{2}$ is different in one week of age in hydration reaction of alite with $\mathrm{C}-\mathrm{S}-\mathrm{H}$ of different $\mathrm{C} / \mathrm{S}$. However, 
in this study, the MCL of generated C-S-H at about 2 days is almost equal. Of course, there are several conditions different from the previous study [Alizadeh et al., 2009] such as hydration time and the amount of added C-S-H. Furthermore, if assuming that MCL is short and a metastable C-S-H is generated is correct as in the previous study [Awamura and Nawa, 2013], it is expected that MCL will increase as age further increases.

From here, authors will consider the mechanism by which the dissolution rate of alite and the amount of $\mathrm{C}-\mathrm{S}-\mathrm{H}$ increase at the early stage of hydration by Seeding of synthesized C-S-H of low C/S. As shown in Figure. 6, C-S-H was formed at 1 hour of age, so it was confirmed that the function of Seeding was demonstrated more strongly in synthesized C-S-H addition system of low C/S than in that of high C/S. Also, from Table 1, the synthesized C-S-H with low C/S has a larger specific surface area than the high C/S synthesized C-S-H. In the previous study, it is reported that particles with a larger specific surface area [Beedle et al., (1989); Jayapalan et al., (1999)] has more strong effect as a crystal nucleating agent when compared with additives having the same composition. Therefore, it was suggested that the synthesized C-S-H with low $\mathrm{C} / \mathrm{S}$ promoted the initial precipitation of $\mathrm{C}-\mathrm{S}-\mathrm{H}$, since the specific surface area of synthesized C-S-H with low C/S was larger than that of high $\mathrm{C} / \mathrm{S}$.

\section{CONCLUSION}

In this study, authors made $\mathrm{C}-\mathrm{S}-\mathrm{H}$ with different $\mathrm{C} / \mathrm{S}$ and conducted detailed characterization of synthesized C-S-H. In addition, the effect of C/S of synthesized C$\mathrm{S}-\mathrm{H}$ on the initial hydration reaction of alite was clarified from the hydration process of alite and MCL of generated C-S-H. As a result, Seeding accelerate not the dissolution of alite but precipitation of C-S-H. Moreover, in synthesized C-S-H of low $\mathrm{C} / \mathrm{S}$ addition system, the formation of $\mathrm{C}-\mathrm{S}-\mathrm{H}$ is promoted more than that of high $\mathrm{C} / \mathrm{S}$ addition system, but the C-S-H formation in the late hydration doesn't depend on the $\mathrm{C} / \mathrm{S}$ of synthesized C-S-H. The MCL of generated C-S-H was different from the MCL of synthesized C-S-H. According to these results, addition of synthesized C-S-H with low $\mathrm{C} / \mathrm{S}$ to cementitious materials may be solve the problem of initial strength of cementitious materials using admixtures such as industrial waste or by-products.

\section{REFERENCES}

T. Oyama et al., (2016), 'The Effect of Sucrose on the Hydration of Alite and Investigation of Hydration Mechanism'. Cement Science and Concrete Technology Vol. 70, pp. 24-31.

Y. Awamura and T. Nawa et al., (2013), 'Effects of Calcium Chloride on the Hydration Kinetics of Alite'. Cement Science and Concrete Technology, Vol. 67, pp. 71-78

G. Land and D. Stephan (2015), 'Controlling Cement Hydration with Nanoparticles'. Cement and Concrete Composites, Vol. 57, pp. 64-67 
L. Nicoleau et al., (2013), 'Oriented Aggregation of Calcium Silicate Hydrate Platelets by the Use of Comb-Like Copolymers'. Soft Matter, Vol. 9, pp. 4864-4874

J.J. Thomas et al., (2009), 'Influence of Nucleation Seeding on the Hydration Mechanisms of Tricalcium Silicate and Cement'. Journal of Physical Chemistry C, Vol. 113, No. 11, pp. 4327-4334

L. Nicoleau, (2010), 'New Calcium Silicate Hydrate Network'. Journal of the Transportation Research Board, No. 2142, pp. 42-51

R. Alizadeh et al., (2009), 'Hydration of Tricalcium Silicate in the Presence of Synthetic Calcium-Silicate-Hydrate'. Journal of Materials Chemistry, Vol. 19, pp. 7937-7946

H.M. Jennings, (1986), 'Aqueous Solubility Relationships for Two Types of Calcium Silicate Hydrate'. Journal of the American Ceramic Society, Vol. 69, No. 8, pp. 614618

R.J. Myers, (2015), 'Effect of Temperature and Aluminium on Calcium (Alumino) Silicate Hydrate Chemistry Under Equilibrium Conditions'. Cement and Concrete Research, Vol. 68, pp. 83-93

R. Hattori et al., (2011), 'Quantification of Intermediate Phase During Hydration of Cement'. Cement Science and Concrete Technology, Vol. 65, pp. 46-53

F. Bellmann et al., (2010), 'Improved Evidence For The Existence Of An Intermediate Phase During Hydration Of Tricalcium Silicate'. Cement and Concrete Research, Vol. 40, pp. 875-884

E. Pustovgar et al. (2016), 'Understanding Silicate Hydration From Quantitative Analyses Of Hydrating Tricalcium Silicates'. Nature communications, Vol. 7, p. 10952

T. Nawa et al., (2015), 'Quantitative Hydrated Silicate Monomer In Hydration Of Alite And Consideration Of Cement Hydration Mechanism'. Cement Science and Concrete Technology, Vol. 69, pp. 2-9

M.D. Andersen et al., (2004), 'Characterization of White Portland Cement Hydration And The C-S-H Structure In The Presence Of Sodium Aluminate By ${ }^{27} \mathrm{Al}$ And ${ }^{29} \mathrm{Si}$ MAS NMR Spectroscopy'. Cement and Concrete Research, Vol. 34, pp. 857-868

S.S. Beedle et al., (1989), 'The Effect Of Fine Pozzolanic And Other Particles On The Hydration $\mathrm{Of}_{3} \mathrm{~S}^{\prime}$. Advanced in Cement Research, Vol. 2, No. 5, pp. 3-8 
A.R. Jayapalan et al., (1999), 'Influence of Additions of Anatase Tio2 Nanoparticles on Early-Age Properties of Cement-Based Materials'. Journal Of The Transportation Research Board, Vol. 2141, Pp .41-46 